\title{
The Current Problem of Oral Health Due to Improper Tooth Brushing in the State of Mexico
}

\author{
María Elena Villaseñor Martínez* \\ Degree in Dentistry from the Autonomous University, Mexico
}

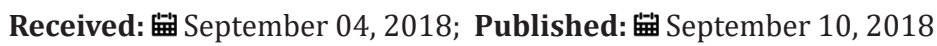

*Corresponding author: María Elena Villaseñor Martínez, Degree in Dentistry from the Autonomous University, Mexico

\section{Opinion}

In ancient times the importance to oral hygiene was already taken, diseases were often considered a punishment of the gods for offenses inflicted on them. Subsequently, dental caries was attributed to vitiated bodily fluids or worms. The medicine of Greek and Roman times are the problems of teething (Hippocrates, 460377 BC, Galen, 130-200 AD) persistent milk teeth (Celso, 25 BC JC $50 \mathrm{Be} \mathrm{JC}$ ) and the presence of erupted teeth in newborns (Pliny the Elder, 23-79 AD JC).In 1743 Rober Bunon, "Father of Pediatric Dentistry." Other authors who also intervened in the birth of this specialty were LT Duchein (1759) and ND Dechément (1804) in France and Z. Fraenkel (1817) in Denmark. In Mexico, caries is a public health problem that affects about $95 \%$ of children under 8 years of age and even $99 \%$ of adults. At present this figure has decreased due to the different prevention programs that have been carried out (fluoridation of drinking water, fluoridation of table salt, etc.), but there are still no bibliographic backups that show us the exact figures of how much the percentage of caries has decreased. The prevalence of caries at national level in the years from 1987 to 1989 was from 80 to $95 \%$ in the different states of the country, and at a global level the prevalence presented discordant parameters, since in the developed countries they have reduced it through control and prevention programs at a massive level (much of Western Europe and North America), and in developing countries like Mexico where the opposite occurs. In response to this problem in 1991, the "National Salt Fluoridation Program" was launched, which seeks to reduce the frequency of dental caries in Mexico. Currently and especially in the preventive area of dentistry, different and diverse methods are available to avoid the dental diseases that most frequently occur in the individual at the early age of the latter.
However, prevention without a change in behavior, or individual or community level, through promotion to health may be diminished. Therefore, parents must instill and motivate a behavior that promotes oral health. This will help the parents to no longer accept tooth decay or gum disease as "something natural" that happens to everyone, and that, just as they go to the doctor when they see any alteration in the body of the In the same way, go to the dentist when they observe any change, no matter how small it is in the mouth of their children, in this way, both parents and children, and especially the latter, must be guided appropriately towards positive behavior. favors or promotes health, in such a way that allows the individual to carry out their individual social activities fully. Therefore, if you consider the growth and development of a child as a continuous process that leads to an independence and achieve to be a person who has confidence in himself, he will begin to interact with his friends and different social groups for his psychological well-being. However, it must be remembered that at the same time this socialization can influence the child to capture or copy behaviors that are not very favorable to their health, especially oral.

It is therefore important that parents know the basic and normal characteristics of their children's mouths. Also, the importance of knowing or remembering that the child, approximately from six months to the preschool stage, will complete his primary teeth in the mouth. From that moment, and until adolescence, all the dental and oral structures already formed and complete will be presented, so that promoting healthy behaviors is invaluable, especially in childhood, as well as reinforcing and motivating them until adolescence, and that if you have good bases from childhood you can continue with this behavior in adulthood. 


\section{(c) (P) This work is licensed under Creative}

To Submit Your Article Click Here: Submit Article

DOI: $10.32474 /$ SJPBS.2018.01.000107

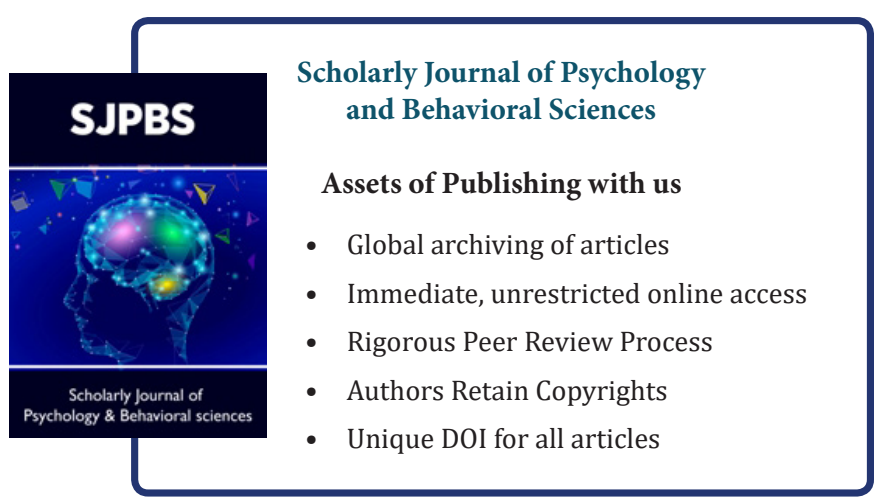

